\title{
Radiotherapy for Thymic Neoplasms
}

\author{
Clifton D. Fuller, M.D. ${ }^{1,3}$, Emma H. Ramahi, B.A. ${ }^{1}$, Noel Aherne, M.D. ${ }^{4}$, Tony Y. Eng, M.D. ${ }^{1}$, \\ and Charles R. Thomas Jr., M.D. ${ }^{3,}{ }^{*}$ \\ ${ }^{1}$ Department of Radiation Oncology, The University of Texas Health Science Center at San \\ Antonio, San Antonio, TX, USA. \\ ${ }^{2}$ Division of Radiological Sciences, Department of Radiology, The University of Texas Health \\ Science Center at San Antonio, San Antonio, TX, USA. \\ ${ }^{3}$ Department of Radiation Oncology, Oregon Health \& Science University, Portland, OR, USA. \\ ${ }^{4}$ Department of Radiation Oncology, North Coast Cancer Institute, University of New South \\ Wales, Australia
}

\begin{abstract}
The role of radiotherapy (RT) in the treatment of thymoma and thymic carcinoma has been evaluated by many investigators over the past two decades. The low incidence of these neoplasms has limited most published studies to small series spanning long time intervals or extant population-based studies. The exact indications and protocols for the use of RT as a part of the multidisciplinary approach to thymoma and thymic carcinoma are still unclear. However, a review of recent literature shows potential benefits for certain patients based on stage and grade of disease as well as the extent of surgical resection.
\end{abstract}

\section{Introduction}

Due to the sensitivity of thymoma and thymic carcinoma to radiation therapy, there is much interest in the role of radiotherapy (RT) in the treatment of these rare neoplasms. Although it is the most common anterior mediastinal compartment neoplasm (Figure 1), [1] low incidence and indolent natural history of the disease have made difficult work of developing definitive recommendations for RT in the multidisciplinary approach to the treatment of thymic neoplasms. In addition, the rapid advances in the delivery of RT make it difficult to evaluate the potential benefit of current treatment practices using data collected over several decades. Currently no domestic randomized prospective clinical trials evaluating the role of adjuvant radiotherapy after complete resection of thymoma or thymic carcinoma have been published. However, retrospective analysis using the Surveillance, Epidemiology, and End Results (SEER) database as well as multiple small case series show potential for the use of adjuvant RT for the treatment of selected subpopulations of patients with thymoma and thymic carcinoma.

Complete surgical resection provides an $82 \% 7$-year survival rate, while incomplete resection and biopsy alone are associated with $71 \%$ and $26 \%$ respectively [2]. Therefore, the mainstay of treatment for thymoma and thymic carcinoma without unresectable/metastatic disease has been en bloc resection of the tumor and adjacent involved structures [3]. There is a potential role for both radiotherapy and chemoradiotherapy to prevent recurrence for patients in whom a complete surgical resection is not possible.

* corresponding author: Department of Radiation Medicine OHSU Knight Cancer Institute 3181 South West Sam Jackson Park Road, KPV4, Portland, OR 97239 Ph 503-494-8758 Fax 503-346-0237 thomasch@ohsu.edu. 


\section{Radiotherapy for Thymoma}

Some investigators in the late 1980s recommended adjuvant RT for all thymic neoplasms regardless of stage or completeness of resection [4-5]. More recent studies have called this practice into question, and current work is focused on the benefit of RT for patients stratified by tumor stage and resection characteristics. Awad and colleagues performed a longitudinal study of patients with Masaoka stage I thymomas (which are completely encapsulated) who underwent complete resection who were followed for 32 years and found a $2 \%$ to $3 \%$ recurrence rate [6], suggesting that adjuvant $\mathrm{RT}$ is unlikely to improve the prognosis in this population of patients. Furthermore, the only randomized prospective trial performed to date, a small $(\mathrm{n}=29)$ series from Peking Union Medical College, demonstrated no survival benefit to RT (88\% 10-year survival) compared to surgery alone (92\% 10-year OS) in Masaoka Stage I patients [7].

Several other investigators also have data to suggest adjuvant RT provides no benefit for localized disease, but potentially benefits Masaoka Stage II and III [8-13] and patients receiving incomplete resections $[8,10,14]$. In higher stage disease, the benefit of adjuvant RT may be more readily detectable. A population-based domestic survival analysis of malignant thymoma analyzing the SEER registry data $(n=599)$ revealed significant overall survival benefit from adjuvant RT for a population comparable to Masaoka Stage II [13]. In a more recent retrospective study also using SEER registry data $(n=901)$, whereas adjuvant RT provided no advantage in terms of overall survival for patients with Masaoka stage I thymoma and thymic carcinoma, a significant increase in overall survival was seen in patients with Masaoka Stage II and III disease, especially when surgery was non-extirpative [15]. However, the SEER registry data include is not coded for surgical resection status (R0/ $\mathrm{R} 1 / \mathrm{R} 2$ ), use of chemotherapy, consistent histopathologic criteria [13], radiation dose, number of fractions, or elapsed days in the treatment course [15]. This limits the further refinement of selection criteria that are possible from SEER data. A retrospective study $(\mathrm{n}=$ 175) has also corroborated the data from these extant population-based studies [16].

In addition, there are data from smaller, mostly institutional series to suggest survival benefit via reduction of recurrences both in the field of radiation and secondary distant progression with adjuvant RT [2, 17-19]. Although not statistically significant, a study of 68 patients by Curran et al. showed local recurrence reaches $47 \%$ at 5 years in patients with Stages II and III disease after an R0 resection without adjuvant RT whereas no recurrence was noted after the addition on adjuvant RT [18]. Likewise, out of 33 patients receiving adjuvant RT, Urgesi et al. showed no in field recurrences and three out of field recurrences [17], lending credence to the efficacy of local control with adjuvant management.

However, several contrasting datasets have also been presented, with countervailing findings regarding RT utilization. In one of the largest series to date, Kondo et al. presented international report of $>1000$ pooled thymoma patients, including 247 Stage II cases, showing no difference between surgery alone and adjuvant RT [14]. A smaller domestic report at the University of Pennsylvania of 167 patients undergoing surgical resection of thymoma showed no benefit from adjuvant RT in margin negative Stage II disease [20]. Several other studies showed no decrease in local or distant recurrence after R0 resection for Stage III thymoma with adjuvant RT [21-24], and Ruffini et al. actually showed worse outcomes with the addition of adjuvant RT [25]. Another recent study of 41 thymoma patients actually showed a significantly longer total survival time in patients with Stage II disease who did not receive adjuvant RT [26]. Likewise, a meta-analysis published in 2009 by Korst et al. utilized data on 592 patients obtained from 13 out of 22 retrospective cohort studies, and showed no benefit of adjuvant RT on recurrence rates after complete resection 
of stage II and/or III thymic epithelial tumors,[27]. Consequently, the use of radiation remains an area of debate and institutional norms.

Adjuvant RT is widely believed to be the standard of care for residual disease after incomplete resections of Stage III and IV disease, however. Curran and colleagues also showed no mediastinal failures after radiation in 26 patients with Stage III thymomas and $79 \%$ recurrence after 5 years without adjuvant RT [18]. Other studies had similar findings with low mediastinal recurrence after treatment with adjuvant RT [17, 19].

Many of the published retrospective studies focus on the benefits of adjuvant RT in terms of survival and recurrence based on stratification by Masaoka stage. More recent studies have focused WHO cell type as a factor in establishing a good candidate group for adjuvant RT. In 2009, Utsumi et al. published a retrospective study of 324 patients who underwent resection of a thymoma in which 119 were treated with adjuvant radiotherapy [28]. When examined based on WHO cell type and Masaoka staging, they showed patients with stage I and II thymoma as well as WHO types A, AB and B1 should not receive adjuvant RT. Also, no significant difference in actuarial disease-specific survival rates were found in patients with stage III and IV disease or WHO cell types B2 and B3 who were and were not treated with adjuvant RT [28].

Although the dose-response relationship for adjuvant $\mathrm{RT}$ is as controversial as the indication(s), RT treatment regimens for thymoma traditionally utilized doses ranging from 30 to $60 \mathrm{~Gy}$ in 1.8 to $2.0 \mathrm{~Gy}$ fractions, delivered over 3 to 6 weeks [5, 16-18, 21, 29-36]. It was thought that 40-45 Gy is sufficient for control of completely resected or microscopic residual disease [37], but in a retrospective study of 175 patients, Zhu and colleagues showed increasing the dose slightly to $50 \mathrm{~Gy}$ might be beneficial [16]. Their data suggested RT dose $>50 \mathrm{~Gy}$ is a prognostic factor for 5-year survival, but extending the radiation field prophylactically did not yield greater local control [16]. Zhu and colleagues suggest that at least 50 Gy should be used for unresectable disease, where as other studies show $>60$ Gy are likely necessary for incompletely resected or gross disease [19, 29]. Sugie and colleagues suggested adjuvant mediastinal RT with 30-40 Gy for Stage II and 50-55 Gy for Stage III prevented local recurrence, and low-dose entire hemithorax irradiation with 11.2 Gy in 7 fractions or 15-16 Gy in 10 fractions after removal of disseminated lesions in the pleura helped to control pleural metastases [38]. Since thymomas have been shown to be sensitive to chemotherapy [39] as well as radiotherapy, multimodality treatment with preoperative chemotherapy and surgical resection followed by adjuvant RT has been shown to increase resectability and survival in patients with stage III and IV thymomas when compared to surgery alone [35, 40-41]. Cisplatin, alone or in combination with other agents (e.g. cyclophosphamide, doxorubicin, vincristine, prednisone or epirubicin) has demonstrated response rates between $77 \%$ and $100 \%$, and pathologic complete response rates between $4 \%$ and $31 \%$ and R0 resections achievable in $57 \%$ to $82 \%$ of cases. Cohort survival with these multimodality regimens ranged between $57 \%$ and $95 \%$, showing that cisplatin-based neoadjuvant chemotherapy, surgery, and adjuvant RT provides excellent results for those with previously unresectable Stage III and IV disease [35, 40-41].

A regimen of combination chemotherapy and definitive radiotherapy has also provided reasonable results for unresectable thymomas. A prospective, phase II intergroup study reported a prolonged progression-free survival in patients treated with 2 to 4 cycles of cisplatin, doxorubicin and cylcophosphamide plus a total dosage of $54 \mathrm{~Gy}$ to the primary tumor and lymph nodes [42]. Patients receiving this combination of therapy had a median survival time of 93 months with a 5-year survival rate of 52.5\% [42]. A phase II study of a multidisciplinary approach to the treatment of locally advanced unresectable malignant thymoma showed treatment with three courses of induction chemotherapy, surgical 
resection, adjuvant RT followed by three courses of consolidation chemotherapy provided a 95\% survival rate and a 77\% progression-free survival rate at 5 years [43].

While adjuvant and definitive RT remain the typical norm, neoadjuvant RT, while rarely utilized in the U.S., provides another approach to multidisciplinary management. In addition to neoadjuvant chemotherapy, Onuki et al. [44] presented an interesting series of Masaoka Stage III thymoma patients $(\mathrm{n}=21)$, involving pre-operative radiotherapy of 12-20 Gy in conventional fractionation, followed by surgical resection 1-3 weeks later. The patient's were then given a median of $40 \mathrm{~Gy}$ (range 22-66.8 Gy) post-operatively. The series, while small, evinced impressive survival, with a 5- and 10-year survival of $91 \%$ and $78 \%$, respectively. Patients who achieved complete resection fared very well, with a 10 -year DFS of $84 \%$.

Adding chemotherapy to neoadjuvant RT, Korst and colleagues are currently recruiting participants for a phase II study investigating the use of preoperative RT with concurrent cisplatin and etoposide in patients with thymoma or thymic carcinoma with significant risk of recurrence shown by $x$-ray and pathology criteria [45]. In this study, preoperative radiation will begin 24 hours after the initiation of chemotherapy at a dose of 4000 to 4500 cGy at 180-200 cGy per fraction, to volume including thymus and gross tumor with $2-2.5 \mathrm{~cm}$ margin. 3D-conformational or IMRT techniques will be used to reduce radiation to nearby structures while delivering higher doses to the tumor itself. Adjuvant RT will be administered to selected patients as determined by Masaoka stage at the time of surgery, WHO pathologic type, and completeness of resection. Trials such as these are necessary to determine with exactitude the optimal regimen and sequence of multimodality management, and enrollment of patients is heavily encouraged.

\section{Radiotherapy for Thymic Carcinoma}

Thymic carcinoma comparatively more rare and aggressive thymic neoplasm than thymoma, with a 5-year survival of 35\% [46]. As with thymomas, surgical resection is the cornerstone of treatment. Prognoses are poor due to early metastases to the pleura and lung, bone, brain and liver, as well as mediastinal, cervical and axillary lymph nodes [46-47]. Contrasting opinions exist on the role of RT in a multimodality regimen, and combination with specific chemotherapeutic agents. As with the treatment of thymoma, there is no consensus on an optimum dose or fractionation. Most studies use a total dose ranging from $40 \mathrm{~Gy}$ to $70 \mathrm{~Gy}$ with daily fractions of 1.8 to $2.0 \mathrm{~Gy}$.

Hsu and colleagues analyzed 26 patients given adjuvant RT and show improved survival and local control with 77\% 5-year survival rate, 91\% 5-year local control rate, and 57\% 5-year distant metastasis-free rate [48]. Radiation dose was found to have a significant association for local control probability in a small series consisting of 27 patients with invasive thymoma and 6 patients with thymic carcinoma [49]. However, Hsu and colleagues also found that, while Masaoka staging was a statistically significant prognostic factor, radiation dose of $<60 \mathrm{~Gy}, 60 \mathrm{~Gy}$, or $>60 \mathrm{~Gy}$ was not a significant predictor of overall survival rate [48]. Ogawa and colleagues showed $100 \%$ control rates in 40 patients with thymic carcinoma who underwent complete resection and adjuvant RT with prescription doses $>50$ Gy [50].

In a larger multi-institutional series of 186 thymic carcinoma patients, Kondo and colleagues showed no survival benefit of adjuvant RT after a subtotal resection [14]. 5-year survival probability for patients with R0 disease receiving adjuvant RT was $73.6 \%$, whereas patients receiving adjuvant chemotherapy, adjuvant chemoradiotherapy and no adjuvant therapy had 5 -year probabilities of $81.5 \%, 46.6 \%$ and $72.2 \%$ respectively [14]. Although heterogeneous chemotherapeutic regimens, radiotherapy dose, and selection bias can provide some 
explanation for these results, these results are derived from the largest extant retrospective series and should be considered by those who advocate adjuvant radiotherapy or chemoradiotherapy for all cases of thymic carcinoma.

Due to the rarity of thymic carcinomas and subsequent small numbers of patients treated, it has been difficult to assess the effectiveness of chemotherapy. Most series have used cisplatin based regimens similar to those used in the treatment of thymoma [51-53]. If the treatment of thymoma provides any indication, it is reasonable to presume the addition of adjuvant RT to chemotherapy and surgery might provide additional survival benefit. While Magois et al. recently presented a series of 9 patients with stage III and IV thymic carcinoma that showed efficacy of neoadjuvant chemotherapy followed by surgical resection and adjuvant radiotherapy or chemoradiotherapy [54], others have suggested surgery remains the best initial treatment option for clearly resectable, well-defined disease, and radiotherapy should be added afterwards if indicated by information gained by surgical staging or pathologic study of the surgical specimen $[14,55]$. Other studies suggest that neoadjuvant chemo or radiotherapy should be initiated only when thymic carcinoma is thought to be unresectable $[49,56]$.

\section{Radiotherapy techniques}

Conventional radiotherapy planning typically utilizes anteroposterior/posteroanterior fields, followed by an opposed oblique beam boost, designed to minimize spinal cord dose (Figures 2-4). More recently, 3D conformal therapy (Figures 2-4) or intensity-modulated radiation therapy (IMRT; Figures 5-8) approaches enable markedly increased conformality, potentiating dose escalation and/or reduction of dose to non-target organs at risk (OARs) (Figures 3 and 4). When using RT to treat thymoma and thymic carcinoma, the heart, lungs, esophagus and spinal cord are at risk, and should be the prioritized OARs for dose constraint, using reasonable constraints derived from thoracic radiotherapy experience. To minimize pulmonary toxicity a V20 restriction of $<30 \%$ and mean lung dose $<20 \mathrm{~Gy}$ are advocated based on lung cancer series, with V13 minimized[57-58]. The entire heart has been purported to tolerate whole heart dose of 35-40 Gy, allowing no more than 1/3 of the myocardium to receive $60 \mathrm{~Gy}$ [14]. It is recommended that the whole heart dose, if feasible, be kept less than $30 \mathrm{~Gy}$ to prevent coronary arterial disease risk amplification [59]. Cord doses should remain $<45 \mathrm{~Gy}$. Although earlier reports found grade 3 and 4 toxicity ranging from $11 \%$ to $13 \%$ [48], newer reports suggest a decreased rate of $5 \%$ to $10 \%$, potentially due to technical innovations in radiotherapy delivery [50]. Death secondary to complications from RT has been reported in $1 \%$ to $13 \%$ of cases [60].

\section{Summary}

Controversy still exists concerning the role of radiotherapy in the treatment of thymic neoplasms. This controversy is unlikely to be resolved in the near future due to the conflicting conclusions of multiple small series and the lack of a large-scale, prospective, randomized trial. Although such as trial is needed to give a definitive algorithm for treatment, low incidence and indolent course of thymic neoplasms, as well as rapid advancement in the radiotherapy technology currently preclude such a study. Currently, the role of adjuvant radiotherapy in the treatment of thymic neoplasms largely depends on the stage of disease and the extent of the surgical resection. Patients with Stage I or completely resected Stage II disease do not seem to derive any appreciable benefit in terms of survival, local control, or recurrence upon the addition of radiotherapy after surgical resection. Thymic neoplasms with favorable histology such as WHO class A, AB and B1 have also been shown not to benefit from adjuvant RT. In contrast, patients with Stage III and IV disease have high enough recurrence rates that the benefits of radiotherapy as part of multimodality therapy shown in certain studies justify its use despite the existence of some 
contrary reports. Additionally, patients having undergone a R1 or R2 extirpation may also benefit for adjuvant RT. More data are necessary to establish a radiation dose-response relationship as well as the incidence of toxicity from treatment. It is important to follow patients indefinitely to monitor for signs of recurrence as well as late toxicity from radiation. In conclusion, a large-scale, multi-center randomized, prospective trial is necessary to develop evidence-based treatment algorithms for thymic neoplasms.

\section{References}

1. Engles EAPR. Malignant thymoma in the United States: demographic patterns in incidence and assoications with subsequent malignancies. International Journal of Cancer. 2003; 105:546-551.

2. Maggi G, Casadio C, Cavallo A, et al. Thymoma: results of 241 operated cases. Ann Thorac Surg. 1991; 51(1):152-6. [PubMed: 1985561]

3. Port J, Ginsberg RJ. Surgery for Thymoma. Chest Surg Clin N Am. 2001; 11(2):421-437. [PubMed: 11413765]

4. Monden Y, Nakahara K, Iioka S, et al. Recurrence of thymoma: clinicopathological features, therapy, and prognosis. Ann Thorac Surg. 1985; 39(2):165-9. [PubMed: 3970610]

5. Nakahara K, Ohno K, Hashimoto J, et al. Thymoma: results with complete resection and adjuvant postoperative irradiation in 141 consecutive patients. J Thorac Cardiovasc Surg. 1988; 95(6):10417. [PubMed: 3374155]

6. Awad WI, Symmans PJ, Dussek JE. Recurrence of stage I thymoma 32 years after total excision. Ann Thorac Surg. 1998; 66(6):2106-8. [PubMed: 9930508]

7. Zhang H, Lu N, Wang M, Gu X, Zhang D. Postoperative radiotherapy for a stage I thymoma: a prospective randomized trial in 29 cases. Chin Med J. 1999; 112(2):136-138. [PubMed: 11593579]

8. Gamondes JP, Balawi A, Greenland T, et al. Seventeen years of surgical treatment of thymoma: factors influencing survival. Eur J Cardiothorac Surg. 1991; 5(3):124-31. [PubMed: 2025438]

9. Regnard JF, Fourquier P, Levasseur P. Results and prognostic factors in resections of primary tracheal tumors: a multicenter retrospective study. The French Society of Cardiovascular Surgery. J Thorac Cardiovasc Surg. 1996; 111(4):808-13. discussion 813-4.

10. Cowen D, Richaud P, Mornex F, et al. Thymoma: results of a multicentric retrospective series of 149 non-metastatic irradiated patients and review of the literature. FNCLCC trialists. Federation Nationale des Centres de Lutte Contre le Cancer. Radiother Oncol. 1995; 34(1):9-16.

11. Wilkens EW, Grillo HC, Scannell Gea. Role of staging in prognosis and management of thymoma. Ann Thorac Surg. 1991; 51:888-92. [PubMed: 2039316]

12. Kaiser LR, Martini N. Clinical management of thymomas: The Memorial Sloan-Kettering Cancer Center experience. Thoracic Surgery: Frontiers and Uncommon Neoplasms. 1989; Vol. 5:176-83. 5.

13. Housman DM, Smith BD, Detterbeck FC, et al. The Role of Radiation Therapy in Malignant Thymomas: A Population-Based Study. International Journal of Radiation Oncology Biology Physics. 2006; 66(3 Supplement):S150.

14. Kondo K, Monden Y. Therapy for thymic epithelial tumors: a clinical study of 1,320 patients from Japan. Ann Thorac Surg. 2003; 76(3):878-84. discussion 884-5. [PubMed: 12963221]

15. Forquer JARN, Fakiris AJ, Loehrer PJ, Johnstone PAS. Postoperative Radiotherapy After Surgical Resection of Thymoma: Differing Roles in Localized and Regional Disease. Int J Radiat Oncol Biol Phys. 2009:1-s6.

16. Zhu G, He S, Fu X, et al. Radiotherapy and prognostic factors for thymoma: a retrospective study of 175 patients. Int J Radiat Oncol Biol Phys. 2004; 60(4):1113-9. [PubMed: 15519782]

17. Urgesi A, Monetti U, Rossi G, et al. Role of radiation therapy in locally advanced thymoma. Radiother Oncol. 1990; 19(3):273-80. [PubMed: 2126388]

18. Curran WJ Jr. Kornstein MJ, Brooks JJ, et al. Invasive thymoma: the role of mediastinal irradiation following complete or incomplete surgical resection. J Clin Oncol. 1988; 6(11):1722-7. [PubMed: 3183702] 
19. Ciernik IF, Meier U, Lutolf UM. Prognostic factors and outcome of incompletely resected invasive thymoma following radiation therapy. J Clin Oncol. 1994; 12(7):1484-90. [PubMed: 8021740]

20. Singhal SSJ, Rosenthal DI, LiVolsi VA, Kaiser LR. Comparison of Stages I-II Thymoma Treated by Complete Resection With or Without Adjuvant Radiation. Ann Thorac Surg. 2003; 76:16351642. [PubMed: 14602300]

21. Blumberg D, Port JL, Weksler B, et al. Thymoma: a multivariate analysis of factors predicting survival. Ann Thorac Surg. 1995; 60(4):908-13. discussion 914. [PubMed: 7574993]

22. Haniuda M, Miyazawa M, Yoshida K, et al. Is postoperative radiotherapy for thymoma effective? Ann Surg. 1996; 224(2):219-24. [PubMed: 8757387]

23. Mangi AA, Wain JC, Donahue DM, et al. Adjuvant radiation of stage III thymoma: is it necessary? Ann Thorac Surg. 2005; 79(6):1834-9. [PubMed: 15919266]

24. Mangi AA, Wright CD, Allan JS, et al. Adjuvant radiation therapy for stage II thymoma. Ann Thorac Surg. 2002; 74(4):1033-7. [PubMed: 12400741]

25. Ruffini E, Mancuso M, Oliaro A, et al. Recurrence of thymoma: analysis of clinicopathologic features, treatment, and outcome. J Thorac Cardiovasc Surg. 1997; 113(1):55-63. [PubMed: 9011702]

26. Vassiliou VTA, Katodritis N, Charoulis N, Koukouma A, Andreopoulos D, Salakou S, Zolota V, Papathanassopoulos P, Christodoulides G, Dougenis D, Kardamakis D. The role of postoperative radiotherapy in the management of patients with thymic tumors -- a retrospective study. In Vivo. 2009; 5:843-852. [PubMed: 19779122]

27. Korst RJKA, Christos PJ, Mandal S. Adjuvant Radiotherapy for Thymic Epithelial Tumors: A Systematic Review and Meta-Analysis. Ann Thorac Surg. 2009; 87:1641-1647. [PubMed: 19379938]

28. Utsumi T, Shiono H, Kadota Y, et al. Postoperative radiation therapy after complete resection of thymoma has little impact on survival. Cancer. 2009

29. Mornex F, Resbeut M, Richaud P, et al. Radiotherapy and chemotherapy for invasive thymomas: a multicentric retrospective review of 90 cases. The FNCLCC trialists. Federation Nationale des Centres de Lutte Contre le Cancer. Int J Radiat Oncol Biol Phys. 1995; 32(3):651-9. [PubMed: 7790251]

30. Ohara K, Okumura T, Sugahara S, et al. The role of preoperative radiotherapy for invasive thymoma. Acta Oncol. 1990; 29(4):425-9. [PubMed: 2390268]

31. Myojin M, Choi NC, Wright CD, et al. Stage III thymoma: pattern of failure after surgery and postoperative radiotherapy and its implication for future study. Int J Radiat Oncol Biol Phys. 2000; 46(4):927-33. [PubMed: 10705015]

32. Akaogi E, Ohara K, Mitsui K, et al. Preoperative radiotherapy and surgery for advanced thymoma with invasion to the great vessels. J Surg Oncol. 1996; 63(1):17-22. [PubMed: 8841462]

33. Arakawa A, Yasunaga T, Saitoh Y, et al. Radiation therapy of invasive thymoma. Int J Radiat Oncol Biol Phys. 1990; 18(3):529-34. [PubMed: 2180868]

34. Urgesi A, Monetti U, Rossi G, et al. Aggressive treatment of intrathoracic recurrences of thymoma. Radiother Oncol. 1992; 24(4):221-5. [PubMed: 1410577]

35. Venuta F, Rendina EA, Longo F, et al. Long-term outcome after multimodality treatment for stage III thymic tumors. Ann Thorac Surg. 2003; 76(6):1866-72. discussion 1872. [PubMed: 14667602]

36. Uematsu M, Yoshida H, Kondo M, et al. Entire hemithorax irradiation following complete resection in patients with stage II-III invasive thymoma. Int J Radiat Oncol Biol Phys. 1996; 35(2): 357-60. [PubMed: 8635944]

37. Ogawa KUT, Toita T, Onishi H, Yoshida H, Kakinohana Y, Adachi G, Itami J, Ito H, Murayama S. Postoperative radiotherapy for patients with completely resected thymoma: a mult-institutional, retrospective review of 103 patients. Cancer. 2002; 94(5):1405-1413. [PubMed: 11920495]

38. Sugie CSY, Ikeya-Hashizume C, Ogino H, Ayakawa S, Tomita N, Bab F, Iwata H, Ito M, Oda K. Invasive thymoma: postoperative mediastinal irradiation, and low-dose entire hemithorax irradiation in patients with pleural dissemination. J Thorac Oncol. 2008; 3(1):75-81. [PubMed: 18166844]

39. Daugaard G, Hansen HH, Rorth M. Combination Chemotherapy for Malignant Thymoma. Ann Intern Med. 1983; 99(2):189-190. [PubMed: 6881774] 
40. Kaghad M, Bonnet H, Yang A, et al. Monoallelically expressed gene related to p53 at 1p36, a region frequently deleted in neuroblastoma and other human cancers. Cell. 1997; 90(4):809-19. [PubMed: 9288759]

41. Macchiarini P, Chella A, Ducci F, et al. Neoadjuvant chemotherapy, surgery, and postoperative radiation therapy for invasive thymoma. Cancer. 1991; 68(4):706-13. [PubMed: 1855170]

42. Loehrer PJ Sr. Chen M, Kim K, et al. Cisplatin, doxorubicin, and cyclophosphamide plus thoracic radiation therapy for limited-stage unresectable thymoma: an intergroup trial. J Clin Oncol. 1997; 15(9):3093-9. [PubMed: 9294472]

43. Kim ESPJ, Komaki R, Walsh GL, Ro JY, Hyung JS, Truong M, Hojin M, Swisher SG, Fossella FV, Khuri FR, Hong WK, Shin DM. Phase II study of multidisciplinary approach with induction chemotherapy, followed by surgical resection, radiation therapy, and consolidation chemotherapy for unresectable malignant thymomas: final report. Lung Cancer. 2004; 44:369-379. [PubMed: $15140551]$

44. Onuki T, Ishikawa S, Yamamoto T, Ito H, Sakai M, Sakakibara Y, Iijima T, Noguchi M, Ohara K. Pathologic Radiorespose of Preoperatively Irradiated Ivasive Thymoma. Journal of Thoracic Oncology. 2008; 3:270-276. [PubMed: 18317070]

45. Korst, R. Phase II Study of Trimodality of Therapy for Patients with Thymoma or Thymic Carcinoma at Significant Risk for Recurrence. ClinicalTrials.gov. 2009.

46. Suster SRJ. Thymic carcinoma: a clinicopathologic study of 60 cases. Cancer. 1991; 67:1025. [PubMed: 1991250]

47. Yano THN, Ichinose Y, et al. Treatment and prognosis of primary thymic carcinoma. J Surg Oncol. 1993; 52:255. [PubMed: 8385724]

48. Hsu HC, Huang EY, Wang CJ, et al. Postoperative radiotherapy in thymic carcinoma: treatment results and prognostic factors. Int J Radiat Oncol Biol Phys. 2002; 52(3):801-5. [PubMed: 11849804]

49. Mayer R, Beham-Schmid C, Groell R, et al. Radiotherapy for invasive thymoma and thymic carcinoma. Clinicopathological review. Strahlenther Onkol. 1999; 175(6):271-8.

50. Ogawa K, Toita T, Uno T, et al. Treatment and prognosis of thymic carcinoma: a retrospective analysis of 40 cases. Cancer. 2002; 94(12):3115-9. [PubMed: 12115342]

51. Chahinian AP. Chemotherapy of thymomas and thymic carcinomas. Chest Surg Clin N Am. 2001; 11(2):447-56. [PubMed: 11413767]

52. Loehrer PJ Sr. Jiroutek M, Aisner S, et al. Combined etoposide, ifosfamide, and cisplatin in the treatment of patients with advanced thymoma and thymic carcinoma: an intergroup trial. Cancer. 2001; 91(11):2010-5. [PubMed: 11391579]

53. Weide LG, Ulbright TM, Loehrer PJ Sr. et al. Thymic carcinoma. A distinct clinical entity responsive to chemotherapy. Cancer. 1993; 71(4):1219-23.

54. Magois E, Guigay J, Blancard PS, et al. Multimodal treatment of thymic carcinoma: Report of nine cases. Lung Cancer. 2008; 59(1):126-32. [PubMed: 17614156]

55. Tseng YL, Wang ST, Wu MH, et al. Thymic carcinoma: involvement of great vessels indicates poor prognosis. Ann Thorac Surg. 2003; 76(4):1041-5. [PubMed: 14529981]

56. Shimada K, Okada Y, Matsumura Y, et al. [Assessment of mode of recurrence after surgical treatment for thymic carcinoma]. Kyobu Geka. 2002; 55(11):976-80. [PubMed: 12391696]

57. Kong FM, Hayman JA, Griffith KA, et al. Final toxicity results of a radiation-dose escalation study in patients with non-small-cell lung cancer (NSCLC): predictors for radiation pneumonitis and fibrosis. Int J Radiat Oncol Biol Phys. 2006; 65(4):1075-86. [PubMed: 16647222]

58. Kong FM, Pan C, Eisbruch A, et al. Physical models and simpler dosimetric descriptors of radiation late toxicity. Semin Radiat Oncol. 2007; 17(2):108-20. [PubMed: 17395041]

59. Adams MJ, Hardenbergh PH, Constine LS, et al. Radiation-associated cardiovascular disease. Crit Rev Oncol Hematol. 2003; 45(1):55-75. [PubMed: 12482572]

60. Lucchi M, Mussi A, Basolo F, et al. The multimodality treatment of thymic carcinoma. Eur J Cardiothorac Surg. 2001; 19(5):566-9. [PubMed: 11343932]

61. Haniuda M, Morimoto M, Nishimura $\mathrm{H}$, et al. Adjuvant radiotherapy after complete resection of thymoma. Ann Thorac Surg. 1992; 54(2):311-5. [PubMed: 1637226] 
62. Jackson MA, Ball DL. Post-operative radiotherapy in invasive thymoma. Radiotherapy and Oncology. 1991; 21(2):77. [PubMed: 1866468]

63. Latz D, Schraube P, Oppitz U, et al. Invasive thymoma: treatment with postoperative radiation therapy. Radiology. 1997; 204(3):859-64. [PubMed: 9280272]

64. Pollack A, Komaki R, Cox JD, et al. Thymoma: treatment and prognosis. Int J Radiat Oncol Biol Phys. 1992; 23(5):1037-43. [PubMed: 1639638]

65. Liu HC, Hsu WH, Chen YJ, et al. Primary thymic carcinoma. Ann Thorac Surg. 2002; 73(4):107681. [PubMed: 11996244]

66. Maruyama R, Suemitsu R, Okamoto T, et al. Persistent and aggressive treatment for thymic carcinoma. Results of a single-institute experience with 25 patients. Oncology. 2006; 70(5):325-9. [PubMed: 17164588]

67. Nakamura Y, Kunitoh H, Kubota K, et al. Platinum-based chemotherapy with or without thoracic radiation therapy in patients with unresectable thymic carcinoma. Jpn J Clin Oncol. 2000; 30(9): 385-8. [PubMed: 11095135]

68. Nonaka T, Tamaki Y, Higuchi K, et al. The role of radiotherapy for thymic carcinoma. Jpn J Clin Oncol. 2004; 34(12):722-6. [PubMed: 15640502] 


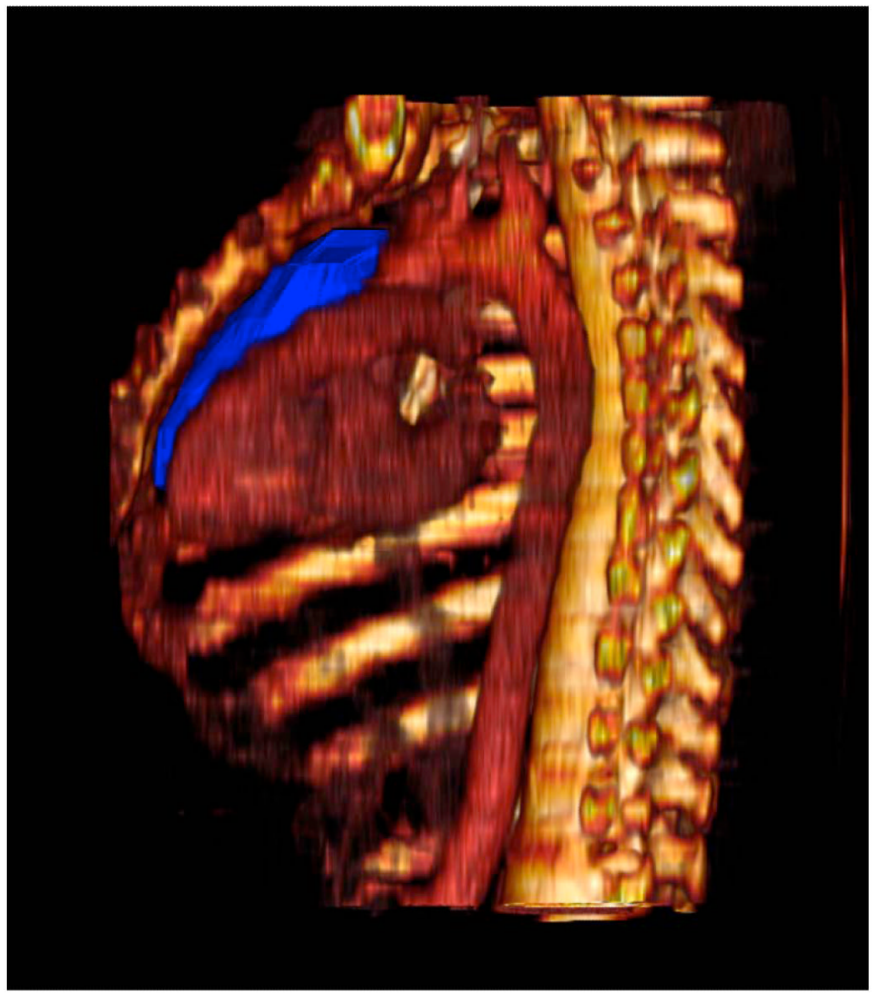

Figure 1.

Sagittal reconstruction of representative thymoma, showing relationship to vascular structures. 

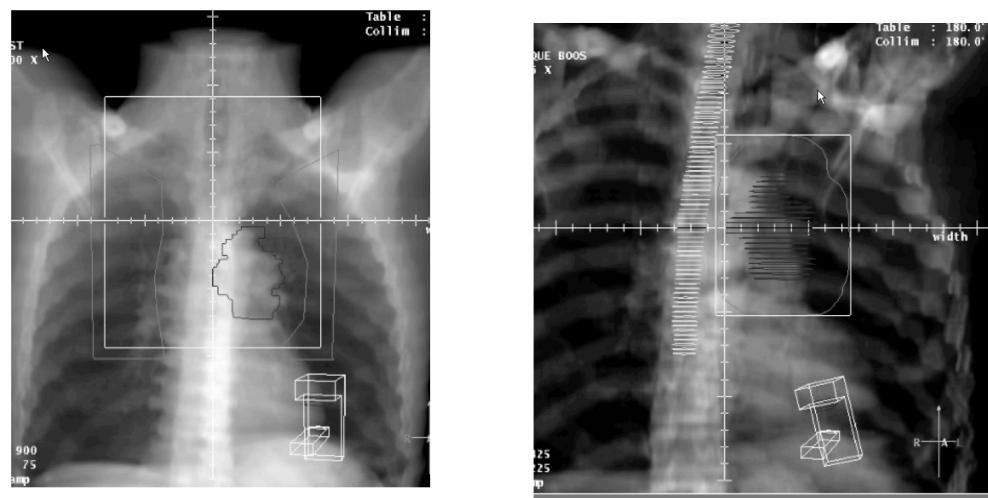

Figure 2.

Typical anteroposterior and oblique off-cord boost fields for conventional three-dimensional therapy. 

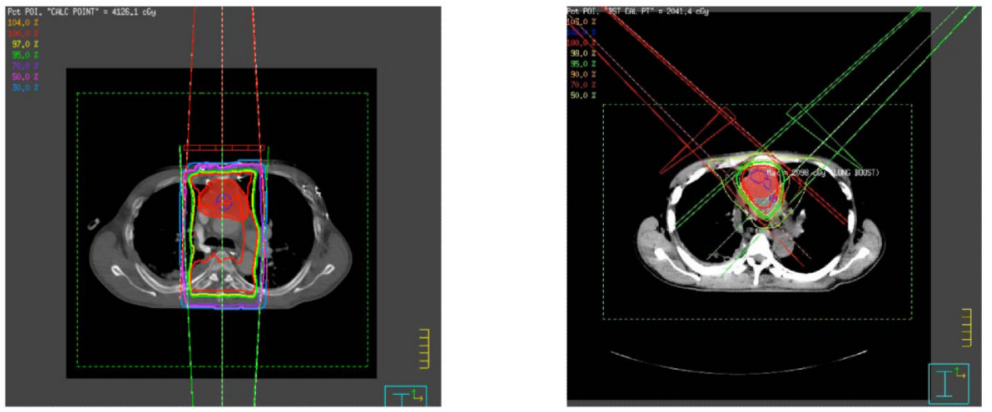

Figure 3.

Axial slices, showing isodose distribution, target volume, and beam geometry for initial anteroposterior fields (left) and off-cord boost (right). 


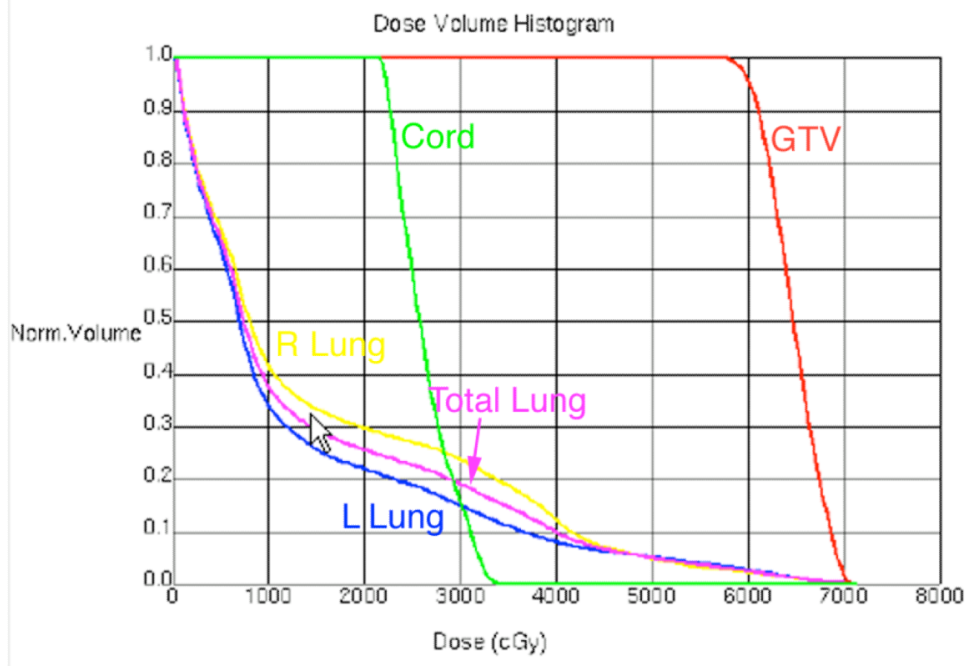

Figure 4.

Composite conventional radiotherapy dose-volume histrogram from patient in Figure 1-3. 


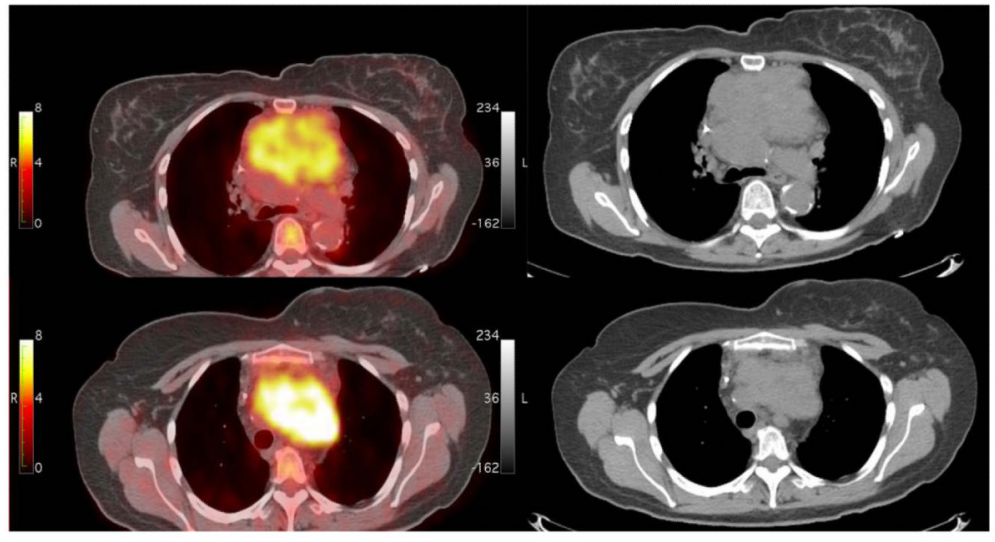

Figure 5.

PET-CT scan of patient with representative 18FDG-avid thymic carcinoma. 


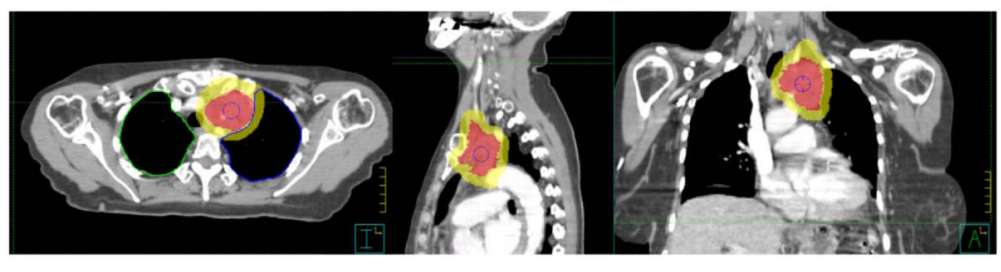

Figure 6.

Target volume reconstruction, showing gross tumor volume (GTV, in red) and planning target volume (PTV, in yellow) in axial, sagittal and coronal reconstructions. 


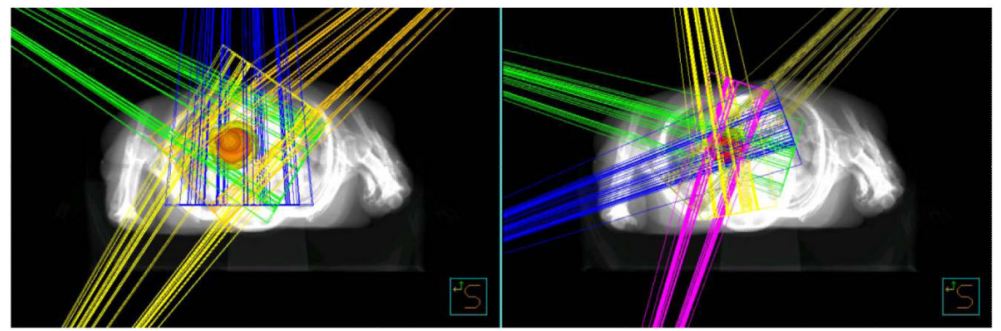

Figure 7.

IMRT beam arrangement for initial treatment (encompassing PTV, treated to $5040 \mathrm{cGy}$, in yellow), at left. Right side depicts reduced volume (treated to $6000 \mathrm{cGy}$ total, in red) boost beam arrangement for thymic carcinoma patient in Figures 5-6. 


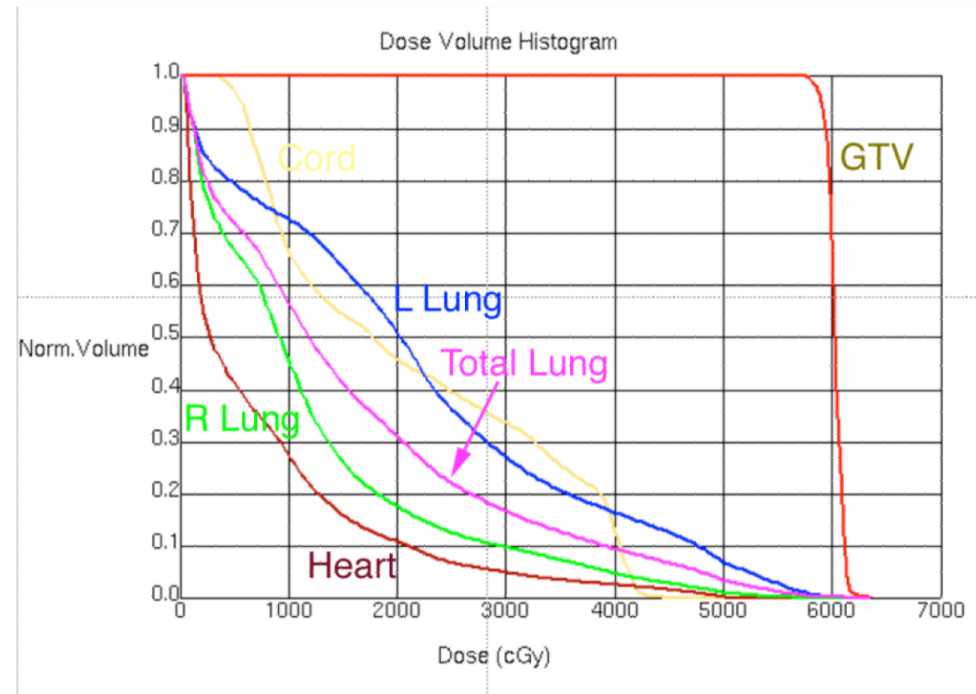

Figure 8.

Composite IMRT dose-volume histrogram from patient in Figure 5-7. 
Table 1

Selected studies detailing radiotherapy outcomes for thymoma

\begin{tabular}{|c|c|c|c|c|c|c|}
\hline Author [reference] & $\begin{array}{l}\text { Masaoka } \\
\text { stage }\end{array}$ & No. & Included RT regimens & Dose Specification (Gy) & $\begin{array}{l}5 \text {-Year local } \\
\text { control }(\%) \\
78.5 \text { series }\end{array}$ & $\begin{array}{l}\text { 5-Year } \\
\text { survival } \\
\text { rate }(\%) \\
59.5 \text { DFS }\end{array}$ \\
\hline \multirow[t]{5}{*}{ Cowen et al [10] } & & & $\begin{array}{l}\text { Preoperative/Postoperative } \\
\pm \text { Chemotherapy }\end{array}$ & $\begin{array}{l}\text { 22-50 Preoperative } \\
\text { 30-70 Postoperative }\end{array}$ & 78.5 series & $59.5 \mathrm{DFS}$ \\
\hline & I & 13 & & & 100 & \\
\hline & II & 46 & & & 98 & \\
\hline & III & 58 & & & 69 & \\
\hline & IVa & 32 & & & 59 & \\
\hline \multirow[t]{5}{*}{ Curran et al [18] } & & & Postoperative (II-IV) & $32-60$ & & \\
\hline & I & 43 & & & & \\
\hline & II & 21 & & & II-III 79 if & 53 \\
\hline & III & 36 & & & $\mathrm{R} 1 / \mathrm{R} 2$ & 53 \\
\hline & IV & 3 & & & 100 if $R 0$ & \\
\hline \multirow[t]{3}{*}{ Forquer et al [15] } & & & Postoperative & NS & & \\
\hline & Localized & 179 & & & - & 81 \\
\hline & Regionalized & 407 & & & - & 76 \\
\hline \multirow[t]{3}{*}{ Haniuda et al [61] } & & & Postoperative & $40-50$ & & \\
\hline & II & 70 & & & 100 & 74 \\
\hline & III & & & & 70 & 69 \\
\hline \multirow[t]{2}{*}{ Jackson [62] } & & & Postoperative & 32-60 (Mean 42) & & \\
\hline & II-III & 28 & & & 61 & 53 \\
\hline \multirow[t]{6}{*}{$\begin{array}{l}\text { Kondo and } \\
\text { Monden [14] }\end{array}$} & & & $\begin{array}{l}\text { Postoperative } \pm \\
\text { Chemotherapy }\end{array}$ & NS & & \\
\hline & I & 552 & & & 99.1 & 100 \\
\hline & II & 247 & & & 95.9 & 98.4 \\
\hline & III & 170 & & & 71.6 & 88.7 \\
\hline & IV & 42 & & & 65.7 & 70.6 (IVa) \\
\hline & & & & & & $52.8(\mathrm{IVb})$ \\
\hline \multirow[t]{3}{*}{ Korst et al [27] } & & & Postoperative & NS & & \\
\hline & II & 197 & & & $75-100$ & - \\
\hline & III & 53 & & & $36-100$ & - \\
\hline \multirow[t]{4}{*}{ Latz et al [63] } & & & $\begin{array}{l}\text { Postoperative } \pm \\
\text { Chemotherapy }\end{array}$ & 10-72 (Median 50) & & \\
\hline & II & 10 & & & 81 & 90 \\
\hline & III & 14 & & & & 67 \\
\hline & IV & 19 & & & & 30 \\
\hline \multirow[t]{4}{*}{ Mornex et al [29] } & & & $\begin{array}{l}\text { Preoperative/Postoperative } \\
\pm \text { Chemotherapy }\end{array}$ & & 30-70 (Median 50) & \\
\hline & IIIa & 21 & & & 86 & 64 \\
\hline & IIIb & 37 & & & $59(\mathrm{IIIb}+\mathrm{IVa})$ & 39 \\
\hline & IVa & 32 & & & & \\
\hline
\end{tabular}




\begin{tabular}{|c|c|c|c|c|c|c|}
\hline Author [reference] & $\begin{array}{l}\text { Masaoka } \\
\text { stage }\end{array}$ & No. & Included RT regimens & Dose Specification (Gy) & $\begin{array}{l}5 \text {-Year local } \\
\text { control }(\%) \\
78.5 \text { series }\end{array}$ & $\begin{array}{l}\text { 5-Year } \\
\text { survival } \\
\text { rate }(\%) \\
59.5 \text { DFS }\end{array}$ \\
\hline \multirow[t]{2}{*}{ Myojin et al [31] } & & & Preoperative/Postoperative & $40-60$ & & \\
\hline & III & 32 & & & 63 & 71 \\
\hline \multirow[t]{5}{*}{ Nakahara et al [5] } & & & Postoperative & $30-50$ & & \\
\hline & I & 45 & & & - & 100 \\
\hline & II & 33 & & & - & 91.5 \\
\hline & III & 48 & & & - & 87.8 \\
\hline & IV & 15 & & & - & 46.6 \\
\hline \multirow[t]{5}{*}{ Pollack et al [64] } & & & Postoperative/Definitive & 50 (Median) & 59 (overall) & \\
\hline & I & 11 & & & & 74 \\
\hline & II & 8 & & & & 71 \\
\hline & III & 10 & & & & 50 \\
\hline & IV & 7 & & & & 29 \\
\hline \multirow[t]{4}{*}{ Singhal et al [20] } & & & Postoperative & $45-55$ & & \\
\hline & I & 3 & & & 100 & - \\
\hline & IIa & 10 & & & 100 & - \\
\hline & $\mathrm{IIb}$ & 10 & & & 90 & - \\
\hline \multirow[t]{2}{*}{ Urgesi et al [17] } & & & Preoperative/Postoperative & $39.6-60$ & & \\
\hline & III & 59 & & & $85-90$ & 78 \\
\hline \multirow[t]{5}{*}{ Utsumi et al [28] } & & & Postoperative & $10-50$ (Mean 39.3) & & \\
\hline & I & 31 & & & - & 77.3 (10OSR) \\
\hline & II & 43 & & & - & 85 (10OSR) \\
\hline & III & 53 & & & - & 79.9 (10OSR) \\
\hline & IV & 7 & & & - & 62.5 (5OSR) \\
\hline \multirow[t]{5}{*}{ Zhu et al [16] } & & & Postoperative & $45-65$ & & \\
\hline & I & 47 & & $\begin{array}{l}(60-65 \text { if } \mathrm{R} 1 / \mathrm{R} 2 ; 50-55 \text { if } \\
\mathrm{R} 0)\end{array}$ & 96.6 & \\
\hline & II & 41 & & & 56.4 & 96 \\
\hline & III & 41 & & & 42.7 & 77.8 \\
\hline & IVa & 32 & & & 21.6 & 56.6 \\
\hline $\mathrm{IVb}$ & 9 & & & & & 35.6 \\
\hline
\end{tabular}


Table 2

Selected studies detailing radiotherapy outcomes for thymic carcinoma

\begin{tabular}{|c|c|c|c|c|c|c|}
\hline Author [reference] & $\begin{array}{l}\text { Patients } \\
\text { in } \\
\text { series }\end{array}$ & Cohort & Subcohort & $\mathbf{n}$ & $\begin{array}{l}\text { 5-year overall } \\
\text { survival }(\%)\end{array}$ & $\begin{array}{l}\text { Median } \\
\text { (mo) }\end{array}$ \\
\hline \multirow{9}{*}{$\begin{array}{l}\text { Blumberg et al } \\
\text { [21] }\end{array}$} & 43 & & & 29 & 65 & - \\
\hline & & Complete resection & Complete resection alone & 5 & 68 & - \\
\hline & & & Complete resection + chemotherapy & 3 & & \\
\hline & & & Complete resection $+\mathrm{RT}$ & 8 & & \\
\hline & & & Complete resection + chemoRT & 13 & & \\
\hline & & Incomplete resection & & & & \\
\hline & & + adjuvant therapy & Incomplete resection + chemotherapy & 1 & 62 & - \\
\hline & & & Incomplete resection $+\mathrm{RT}$ & 6 & & \\
\hline & & & Incomplete resection + chemoRT & 6 & & \\
\hline \multirow[t]{3}{*}{ Hsu et al [48] } & 26 & Surgery $+\mathrm{RT}$ & & & 77 & \\
\hline & & & $>60 \mathrm{~Gy}$ & 17 & - & \\
\hline & & & $<60 \mathrm{~Gy}$ & 9 & - & \\
\hline \multirow{10}{*}{$\begin{array}{l}\text { Kondo and } \\
\text { Monden [14] }\end{array}$} & 186 & & & & 50.5 & \\
\hline & & Surgery alone & & 24 & 72.2 & \\
\hline & & Surgery + adjuvant & & 105 & - & \\
\hline & & Surgery + RT & Total resection $+\mathrm{RT}$ & 46 & - & \\
\hline & & Surgery + chemoRT & Total resection + chemoRT & 33 & 73.6 & \\
\hline & & $\begin{array}{l}\text { Surgery }+ \\
\text { chemotherapy }\end{array}$ & Total resection + chemotherapy & 41 & - & \\
\hline & & No surgery & & 24 & 46.6 & \\
\hline & & RT & & 18 & - & \\
\hline & & ChemoRT & & 12 & 81.5 & \\
\hline & & Chemotherapy & & 24 & 24.2 & \\
\hline \multirow[t]{5}{*}{ Liu et al [65] } & 38 & Completely resected & - & 15 & & 35 \\
\hline & & Incomplete resection & RT alone & 6 & & 14 \\
\hline & & & Chemotherapy & 3 & & 21.4 \\
\hline & & & ChemoRT & 8 & & 17.3 \\
\hline & & & No adjuvant therapy & 4 & & 4.1 \\
\hline \multirow[t]{3}{*}{ Lucci et al [60] } & 7 & Induction & & 7 & 71.4 & \\
\hline & & chemotherapy + & Complete resection/45Gy & 4 & 71.4 & \\
\hline & & surgery + XRT & Incomplete resection/60Gy & 3 & & \\
\hline \multirow[t]{5}{*}{ Magois et al [54] } & 9 & Surgery + RT & & 1 & & 20 \\
\hline & & Surgery + chemoRT & & 2 & & \\
\hline & & ChemoRT & & 1 & & \\
\hline & & Chemotherapy & & 3 & & \\
\hline & & $\begin{array}{l}\text { Surgery }+ \\
\text { chemotherapy }\end{array}$ & & 2 & & \\
\hline
\end{tabular}




\begin{tabular}{|c|c|c|c|c|c|c|}
\hline Author [reference] & $\begin{array}{l}\text { Patients } \\
\text { in } \\
\text { series }\end{array}$ & Cohort & Subcohort & $\mathbf{n}$ & $\begin{array}{l}\text { 5-year overall } \\
\text { survival }(\%)\end{array}$ & $\begin{array}{l}\text { Median } \\
(\text { mo })\end{array}$ \\
\hline \multirow{7}{*}{$\begin{array}{l}\text { Maruyama et al } \\
\text { [66] }\end{array}$} & 25 & & & 4 & 31 & 32 \\
\hline & & Surgery & & 3 & & \\
\hline & & Surgery + & & 6 & & \\
\hline & & RT/Chemotherapy & & & & \\
\hline & & RT & & 3 & & \\
\hline & & ChemoRT & & 12 & & \\
\hline & & Chemotherapy & & 9 & & \\
\hline \multirow{2}{*}{$\begin{array}{l}\text { Nakamura et al } \\
{[67]}\end{array}$} & 10 & ChemoRT & & 8 & & 11 \\
\hline & & Chemotherapy & & 2 & & \\
\hline \multirow[t]{3}{*}{ Nonaka et al [68] } & 12 & & & & 25 & 24 \\
\hline & & RT & & & 33 & 28 \\
\hline & & no RT & & & 0 & 12 \\
\hline \multirow[t]{7}{*}{ Ogawa et al [50] } & 40 & Surgery & $\begin{array}{l}\text { Induction chemotherapy }+ \text { surgery }+ \\
\text { XRT }\end{array}$ & 6 & & \\
\hline & & & Surgery + RT + chemotherapy & 4 & 38 & \\
\hline & & & Surgery + RT & 17 & 27 & \\
\hline & & No surgery & Chemotherapy $+\mathrm{RT}$ & 10 & 44 & \\
\hline & & & $\mathrm{RT}$ & 3 & & \\
\hline & & & $>60 \mathrm{~Gy}$ & 15 & & \\
\hline & & & $<60 \mathrm{~Gy}$ & 25 & & \\
\hline
\end{tabular}

